\title{
The Construction of Performance Evaluation Index System for Strategic Emerging Enterprises in China
}

\author{
Chao ZENG ${ }^{1, a}$, Peiwen Zhang ${ }^{2}$ \\ 1 Jiangxi Normal University Science and Technology College, China \\ 2 Jiangxi Normal University Business College, China \\ ajxsdjh@vip.sina.com
}

Keywords: Strategic emerging industry, Performance evaluation, System construction

\begin{abstract}
The development of strategic emerging industries is a major strategic choice for China's development of the economy in the new era. In order to promote the important role of the high-tech zone in leading the development of emerging enterprises, the Ministry of Science and Technology has proposed an industrialization strategy to promote scientific and technological achievements related to emerging enterprises. This paper expounds the characteristics of China's strategic emerging enterprises, analyzes the factors affecting the performance of strategic emerging enterprises, and follows the principle of setting certain indicators, respectively sets performance evaluation indicators of corresponding dimensions, and constructs performance evaluation indicators applicable to strategic emerging enterprises in China.
\end{abstract}

\section{Introduction}

All Strategic emerging enterprises refer to emerging technologies, high technology content, short time-out and rapid development, good market prospects, and large spillover effects. They can drive a group of enterprises to rise and have strategic support for national economic and social development. It will eventually become the format of the dominant industry and pillar industries. Starting from China's national conditions, science and technology, and industrial base, the seven industries of energy conservation and environmental protection, new generation information technology, biology, high-end equipment manufacturing, new energy, new materials and new energy vehicles are selected as strategic emerging industries. Strategic emerging companies and traditional enterprises require rational allocation, utilization of natural resources, and rely on a large amount of equipment, funds, etc.

\section{Factors affecting the performance of strategic emerging companies}

\subsection{Financial resources}

Strategic emerging companies have high R\&D costs, large initial investment, long recycling period, and strong financial strength to back up. In the strategic emerging enterprise operation activities, due to the arduousness and complexity of strategic emerging enterprise development and its large amount of human and material consumption, high-tech products are characterized by originality and high precision, requiring production equipment, testing methods, Investment in the working environment and raw material supply is also high. The high investment during high-tech development often makes enterprises with rich financial resources more innovative, and they tend to occupy new markets by developing new products and obtain higher profits. Therefore, obtaining financial support is an important factor in the growth of strategic emerging companies. Strong financial strength includes two aspects: First, there must be sufficient self-owned funds; second, it must have good financing capabilities. Both ample self-owned funds and good financing capabilities promote and complement each other to a certain extent. Therefore, strong financial strength is a strategic emerging company. 


\subsection{External stakeholders}

The external stakeholders of the enterprise mainly refer to the individuals or units outside the enterprise that can affect the internal operation and the effect of the enterprise. In the strategic management of strategic emerging enterprises, customers, suppliers, financial institutions and governments are the four most important factors affecting the enterprise. Stakeholders. Customer satisfaction with the product and the company will affect the company income. The price, quality, and timeliness of raw materials provided by suppliers will affect the quality and cost of the products, which in turn will affect their competitiveness in the same industry and ultimately affect the profitability of the company. In addition, due to strategic emerging companies Usually capital-intensive enterprises have great requirements for capital investment, except for investing in venture capital, financial institutions' loans are also crucial for enterprises. The adequacy of funds will directly affect the development potential of enterprises.

\section{The principle of performance evaluation indicators design}

\subsection{The principle of operability and scientific practicability}

The so-called operability can be implemented, that is, the evaluation indicators we set should be concise, the data needed to calculate the indicators should be relatively easy to obtain, and the access method is simple, and the designed indicators can be accurate in the application process. The measure of the object being evaluated. Designing any indicator should be based on practicality and reasonable evaluation of the company's performance. If the performance evaluation system is too large, it will affect the evaluation effect of the enterprise. At the same time, too many levels and too small indicators will affect the judgment of the evaluation results. Similarly, if the evaluation index system is too small and the indicator design is too broad, the actual situation of the company's performance will not be fully disclosed. In addition, the principle of "seeking truth from facts" must be followed when setting evaluation indicators.

\subsection{Comprehensive and systematic principles}

Strategic emerging enterprises should follow the comprehensive and systematic principles when setting corresponding indicators. The set indicators can comprehensively evaluate the evaluation of strategic emerging enterprise performance is the most basic, and the comprehensive evaluation of the performance of enterprises depends on the indicators set by enterprises. Rationality. On the one hand, the design of the indicator system should take into account the impact. The main aspects of the company's strategic goals or competitive advantages, in order to evaluate the performance of the company from different perspectives; on the other hand, should also consider the systemic and inter-connectivity between the indicators, so that the indicator system not only Can fully reflect the current status of the company, and should be reflected in the set evaluation indicators.Judging the future development trend of the company.

\section{Basic ideas for performance evaluation of strategic emerging enterprises}

\subsection{Using the Balanced Scorecard as the basis for the evaluation system}

The Balanced Scorecard provides a systematic and comprehensive assessment of corporate performance. From the performance influencing factors of the above-mentioned strategic emerging enterprises, it can be seen that the performance success of strategic emerging enterprises is obtained by a variety of interrelated factors. It is the result of the joint efforts of various factors, so the performance evaluation of strategic emerging enterprises is required. Focusing on the various factors affecting the evaluation results, these requirements are in line with the characteristics that the Balanced Scorecard can comprehensively evaluate the performance of the enterprise. This paper will build a performance evaluation index system for strategic emerging enterprises based on the 
balanced scorecard. Since the Balanced Scorecard not only considers the financial level, but also considers other business aspects, it is more comprehensive in assessing the enterprise.

\subsection{Improvement of Balanced Scorecard in Performance Evaluation of Strategic Emerging Industries}

Expanding its customer dimension to social responsibility dimension.Strategic emerging enterprises are essentially affiliated with high-tech enterprises. Because of the comparison between strategic emerging enterprises and general enterprises, they also need to be able to drive a group of industries to rise and play a strategic supporting role in national economic and social development. Therefore, the evaluation of strategic emerging enterprises should focus on their contribution to the entire economy and society. Therefore, social responsibility alone is taken as a dimension for the performance evaluation of strategic emerging enterprises. Emphasizing R\&D and innovation capabilities in business processes.Among strategic emerging companies, the role of innovation capability is becoming more and more important. Traditional balanced scorecards are far from meeting the needs of investigating R\&D innovation performance. Therefore, it is necessary to add new indicators to strengthen $R \& D$ according to the characteristics of strategic emerging companies. Innovation performance evaluation.

\section{Design of performance evaluation indicators for strategic emerging enterprises}

\subsection{Financial dimensions}

\subsection{1 solvency is the ability of corporate assets to repay.}

short-term and long-term debt, and is a key factor reflecting the viability of enterprises. Strategic emerging companies often require large capital investment in research and development, and debt is often more than traditional enterprises. The asset-liability ratio and the current ratio indicator reflect the solvency of the company. Assets and liabilities. The indicator reflects the proportion of corporate debt in total assets. The higher the value indicates the stronger the company's expectation of its solvency; the current ratio is a reliable indicator of the company's short-term solvency, due to the timing of strategic emerging companies. The land needs more capital investment, so this indicator is very important and generally proportional to short-term solvency.

5.1.2 Profitability is the ability of an enterprise to obtain profits.

The profitability of an enterprise is the most concerned issue of corporate stakeholders. It is directly reflected in the amount of inflow profits in the company's operating income. It also indicates whether the company has good investment opportunities and development prospects in the future. The ROE indicator reflects the profitability of the company, which reflects the ability of the manager to invest in the proceeds of the investor. This is a comprehensive indicator for evaluating the relationship between investment and compensation. The higher the return on net assets, the higher the The stronger the capital profitability. In general, the characteristics of high-tech in strategic emerging companies are directly reflected in their high return on net assets.

\subsection{Social responsibility dimension}

\subsubsection{Strategic emerging enterprises have strategic support for national economic and social development.}

The social contribution rate and social accumulation rate are used to measure the social contribution of strategic emerging enterprises. The social contribution rate is used to evaluate the enterprise's use of all assets for the country or The ability of society to create or pay value reflects the fulfillment of corporate social responsibility to a certain extent. Enterprises mainly protect the interests of the government by paying taxes, and the amount of tax is stipulated by the tax law. The autonomy of enterprises is very small, so the government interests and social interests are combined into one here. Compared with the social responsibility that the enterprise should bear, the true social responsibility of the enterprise can better reflect the contribution of the enterprise because it is embodied by the 
actual cash flow, reflecting the amount of cash contributed by the enterprise under the established income, thus representing the enterprise. The level of social responsibility assumed.

5.2.2 The development of strategic emerging enterprises is based on high-tech enterprises.

If they want to develop rapidly, they must use high-tech enterprises as a platform. In recent years, the state has focused on fostering and encouraging enterprises to develop high-tech, and has given a large amount of government subsidies. Among them, strategic emerging companies have the responsibility to disclose company information, in order to the situation is supervised, the board of directors is set up within the company, and one third of the independent directors must be established in the board of directors. Therefore, the situation of corporate governance structure can be reflected by the proportion of directors who are independent directors.

\subsection{Learning and Growth Dimensions}

5.3.1 Growth potential is the ability of an enterprise to accumulate wealth, which is consistent with the business objectives of traditional enterprises.

The growth rate of net fixed assets directly reflects the proportion of wealth growth of enterprises in a certain period of time. Because strategic emerging enterprises have rapid growth, this indicator is often reflected in strategic emerging enterprises, which is more important than traditional enterprises.

5.3.2 Growth investment Specific to strategic emerging companies is the company's investment in research and development.

Because the high-tech relied on by strategic emerging companies often requires a lot of manpower and material resources, the degree of investment in R\&D is worthy of attention, and the proportion of $R \& D$ expenses to sales profit is a good reflection of the above problems.

\section{Conclusion}

The determination of the dimension should be based on the specific circumstances of the specific enterprise, and the focus cannot be rigidly focused on these four dimensions, so that the scope of the key elements is limited, so the key to the possible inclusion of multiple dimensions Factors should be given special attention and attention. In addition, if the actual situation of the enterprise requires more evaluation factors, the enterprise can set one or two necessary aspects according to its own situation. Simple and intuitive is the basic feature of the Balanced Scorecard, which helps stakeholders to clearly and objectively evaluate business performance.

\section{Acknowledgements}

This paper is one of the research results of The Construction Evaluation Model and Analysis of Influencing Factors of Enterprise Group Performance under Strategic Orientation in The Research Project of the Science and Technology of Jiangxi Provincial Department of Education.

\section{References}

[1] Research on the status quo and countermeasures of the development of strategic emerging industries in Nanjing [J]. Xue Fengguan, Ji Fangtong. Nanjing Social Sciences. 2017(12)

[2] Analysis of influencing factors of technological innovation in strategic emerging industries based on structural equation model [J]. Li Yuhua, Wang Yueming, Hu Yaowei. Research Management. 2015(08)

[3] Research on early warning mechanism of patent emerging enterprise patent risk [D]. Guo Yu. Harbin University of Science and Technology.2015 